(15\%), tăng men gan (11,3\%), đều mức độ nhe đến vừa. Không có biến chứng giãn não thất, hoại tử mô não lành sau xạ phẩu. Tiêu chảy gặp nhiều ở nhóm điều trị bằng Afatinib hơn Erlotinib và Gefitinib, sư khác biêt có ý nghĩa thống kê với $\mathrm{p}<0,05$. Đa số bệnh nhân tuân thủ phác đồ, độc tính mức độ vừa làm 2 bệnh nhân phải tạm dừng thời gian ngắn, 2 bệnh nhân giảm liều.

\section{TÀI LIẸU THAM KHẢO}

1. Sung $H$, Ferlay J, Siegel $R$ L (2021). "Global Cancer Statistics 2020: GLOBOCAN Estimates of Incidence and Mortality Worldwide for 36 Cancers in 185 Countries". 71 (3), 209-249.

2. Davis F G, Dolecek T A, McCarthy B J, et al (2012). "Toward determining the lifetime occurrence of metastatic brain tumors estimated from 2007 United States cancer incidence data". Neuro Oncol, 14 (9), 1171-1177.

3. Mai Trong Khoa (2020). Hướng dẫn chẩn đoán và điều trị một số bệnh lý ung bướu, Nhà xuất bản Y học,

4. Mok $T S, W i \quad Y L$, Thongprasert $S$, et al (2009). "Gefitinib or carboplatin-paclitaxel in pulmonary adenocarcinoma". N Engl J Med, 361 (10), 947-957.

5. Lê Thu Hà (2017). Đánh giá hiệu quả thuốc Erlotinib trong điêu trị ung thư phổi biểu mô tuyến giai đoạn muộn, Luận án Tiến sỹ y học, Trương Đại học y Hà Nối.

6. Pham Văn Thái (2014). Nghiên cứu điều tri ung thư phổi không tế bào nhỏ di căn não bằng hoá xạ trị, Luận án Tiến sỹ y học, Trường Đại học y Hà Nôii.

7. Park K, Tan E H, O'Byrne $K$, et al (2016). "Afatinib versus gefitinib as first-line treatment of patients with EGFR mutation-positive non-smallcell lung cancer (LUX-Lung 7): a phase 2B, openlabel, randomised controlled trial". Lancet Oncol, 17 (5), 577-589.

8. Nan $X$, Xie C, Yu $X$, et al (2017). "EGFR TKI as first-line treatment for patients with advanced EGFR mutation-positive non-small-cell lung cancer". Oncotarget, 8 (43), 75712-75726.

9. Yang $\mathbf{S} \mathbf{H}, \mathbf{K i m} \mathbf{H} \mathbf{Y}$ (2020). "The Effect of Epidermal Growth Factor Receptor Mutation on Intracranial Progression-Free Survival of Non-Small Cell Lung Cancer Patients with Brain Metastasis Underwent Gamma Knife Radiosurgery". 8 (2), 103-108.

\title{
THIẾT LÂP KHOẢNG NỒNG Độ CỦA SÁU THÔNG Số THƯỜNG QUY AST, ALT, CHOLESTEROL, TRIGLYCERIDE, GLUCOSE VÀ PROTEIN TRONG CHẾ TẠO MẪU NGOẠI KIỂM HÓA SINH
}

Trần Hưuu Tâm*, Trương Quân Thụy*, Vũ Đình Dũng*, Nguyễn Thị Hồng Phương*, Nguyễn Thị Ngọc Vân*, Vũ Thị Như Oanh*, Nguyễn Đàm Châu Bảo*

\section{TÓM TẮT}

Xét nghiệm hóa sinh là một trong những chỉ định cận lâm sàng thường quy nhất tại các đơn vị y tế, các xét nghiệm này là căn cứ góp phần giúp các nhà lâm sàng đựa ra quyết định quan trọng cho công tác điều trị, chẩn đoán sớm và dự phòng bệnh, nghiên cứu khoa học trong y học,... Một trong nhứng công tác nhẳm đảm bảo đô tin cây và chất lương của xét nghiệm hóa sinh là ngoại kiểm tra chất lượng xét nghiềm $[1,2,3]$. Để chế tao mẫu ngoai kiểm cần có khoảng nồng độ cao, thấp, bình thường của các thông số đế sử dung trong quá trình pha chế mẫu. Sáu thông số hóa sinh thường quy được khảo sát gồm protein glucose, cholesterol, triglyceride, AST, ALT. Kết quả thu được khoảng nồng độ cao của glucose là $9,50-24,00 \mathrm{mmol} / \mathrm{L}$, protein là $95-115 \mathrm{~g} / \mathrm{L}$, cholesterol là $6,20-9,00 \mathrm{mmol} / \mathrm{L}$, triglyceride là 2,70 $9,50 \mathrm{mmol} / \mathrm{L}$, AST là 95 - $350 \mathrm{U} / \mathrm{L}$, ALT là $95-300 \mathrm{U} / \mathrm{L}$;

*Trung tâm Kiểm chuẩn Xét nghiệm TP.HCM

Chịu trách nhiệm chính: Trần Hữu Tâm

Email: trhuutam@yahoo.com

Ngày nhận bài: 23.6.2021

Ngày phản biện khoa học: 20.8 .2021

Ngày duyệt bài: 26.8.2021 khoảng nồng đô thâp của glucose là 2,49 - 3,90 $\mathrm{mmol} / \mathrm{L}$, protein là $10-40 \mathrm{~g} / \mathrm{L}$, cholesterol là $2,50-$ $3,70 \mathrm{mmol} / \mathrm{L}$, triglyceride là $0,20-1,00 \mathrm{mmol} / \mathrm{L}$, AST là 7 - $24 \mathrm{U} / \mathrm{L}$, $A L T$ là 7 - $24 \mathrm{U} / \mathrm{L}$; khoảng nồng độ bình thường của glucose là $4,00-9,00 \mathrm{mmol} / \mathrm{L}$, protein là $45-90 \mathrm{~g} / \mathrm{L}$, cholesterol là $3,80-6,10 \mathrm{mmol} / \mathrm{L}$, triglyceride là $1,10-2,60 \mathrm{mmol} / \mathrm{L}, A S T$ là $25-94 \mathrm{U} / \mathrm{L}$, ALT là 25-94 U/L.

Tư khóa: ngoại kiểm tra, nội kiểm tra.

\section{SUMMARY}

\section{CONCENTRATION RANGES OF SIX ROUTINE \\ PARAMETERS AST, ALT, CHOLESTEROL, TRIGLYCERIDE, GLUCOSE AND PROTEIN FOR CREATING CLINICAL CHEMISTRY EXTERNAL QUALITY ASSESSMENT SAMPLES}

Clinical chemistry test is one of the most routine indications in medical units, it is basic in helping clinicians make important decisions for treatment, early diagnosis and disease prevention, scientific research in medicine,... One of the tasks to ensure the reliability and quality of biochemical tests is external quality assessment $[1,2,3]$. To make an external quality assessment sample, the level of high, low and normal concentration range of the parameters is required for using in the sample preparation process. Six routine clinical chemistry parameters were 
investigated including protein, glucose, cholesterol, triglyceride, AST, ALT. The results, high concentration range of glucose is $9,50-24,00 \mathrm{mmol} / \mathrm{L}$, protein is 95 - $115 \mathrm{~g} / \mathrm{L}$, cholesterol is $6,20-9,00 \mathrm{mmol} / \mathrm{L}$, triglyceride is $2,70-9,50 \mathrm{mmol} / \mathrm{L}$, AST is $95-350$ $\mathrm{U} / \mathrm{L}$, ALT is $95-300 \mathrm{U} / \mathrm{L}$; The low concentration range of glucose is $2,49-3,90 \mathrm{mmol} / \mathrm{L}$, protein is $10-40$ $\mathrm{g} / \mathrm{L}$, cholesterol is $2,50-3,70 \mathrm{mmol} / \mathrm{L}$, triglyceride is $0,20-1,00 \mathrm{mmol} / \mathrm{L}$, AST is $7-24 \mathrm{U} / \mathrm{L}, \mathrm{ALT}$ is $7-24$ $\mathrm{U} / \mathrm{L}$; The normal concentration range of glucose is $4,00-9,00 \mathrm{mmol} / \mathrm{L}$, protein is $45-90 \mathrm{~g} / \mathrm{L}$, cholesterol is $3,80-6,10 \mathrm{mmol} / \mathrm{L}$, triglyceride is $1,10-2,60$ $\mathrm{mmol} / \mathrm{L}, A S T$ is $25-94 \mathrm{U} / \mathrm{L}, A L T$ is $25-94 \mathrm{U} / \mathrm{L}$.

Keywords: external quality assessment, internal quality control

\section{I. ĐặT VẤN ĐỀ}

Các thông số hóa sinh lâm sàng khác nhau về tuổi tác, giới tính, lối sống, môi trường và yếu tố di truyền.Việc nghiên cứu và đưa ra các khoảng tham chiếu được thực hiện trên một quần thể nhất định trên quốc gia hoặc vùng lã̃nh thổ. Do đó, các giá trị ngưỡng cao và thấp dùng để phát hiện và chẩn đoán bệnh ở các nước và vùng lãnh thổ sẽ khác nhau [4]. Khoảng tham chiêu khác nhau đáng kể giữa các phòng xét nghiệm khác nhau, phụ thuộc vào phương pháp và thiết bị sử dụng. Điều này đặc biệt đúng đối với các enzyme trong huyết thanh vì các phương pháp có thể thay đổi về $\mathrm{pH}$, nhiệt độ, chất gẳn kết enzyme đặc hiệu và cơ chất sử dụng trong phàn ứng [5].

Hiện nay, trên thế giới các khoảng tham chiêuu, ngưỡng cao và thấp của các thông số Hoá sinh đã được các tổ chức cập nhật và tổng hợp, điển hình như tổ chức ABIM (American Board of International Medicine) ớ Mỹ, tổ chức NHS (National Health Service) ở Anh, CLSI (Clinical \& Laboratory Standards Insititue) ở Mỹ, Nordic Reference Interval Project 2000 (NORIP), Centers for Disease Control and Prevention (CDC), American Diabetes Association (ADA), WHO.... O' nước ta, Bộ y tế cũng đưa ra các khoảng tham chiếu cho từng thông số Hoá sinh và Huyêt học dựa trên thể trạng đặc trưng của người Việt Nam (quyết định số 320/QD-BYT). Chúng tôi sẽ dựa trên các khoảng tham chiếu trên thế giới và Việt Nam, ngưỡng giá trị cao và thấp tham khảo từ mẫu nội kiểm Randox và khoảng giá trị đo phân tích (Analytical Measurement Range - AMR) của các dòng máy hoá sinh tự động (Beckman Coulter, Abbott, Mindray, Erba,...) để lựa chọn khoảng nồng độ bình thường, cao và thấp cho 6 thông số hoá sinh: glucose, protein, cholesterol, triglyceride, AST, ALT.

\section{II. ĐỐI TƯợNG VÀ PHƯƠ'NG PHÁP NGHIÊN CỨU 2.1. Đối tượng}

- Các tài liệu y văn về khoảng tham chiếu của các tổ chức CLSI, CDC, WHO, NHS, ADA, Bộ y tế...

- 5 phòng xét nghiệm hóa sinh lâm sàng sử dụng các dòng máy của Beckman Coulter, Abbott Architect, Mindray, Roche, Erba.

\subsection{Phương pháp}

- Thu thập các số liệu về các khoảng nồng độ cao, thấp, bình thường trên các tài liệu của CLSI, CDC, WHO, ABIM, NHS, ADA, NORIP, Bộ y tế cho 6 thông số hóa sinh AST, ALT, glucose, protein, cholesterol, triglyceride.

Điều chế 5 bộ mâuu với các nồng độ cao, thấp, bình thường để phân tích ở 5 phòng xét nghiệm chạy các dòng máy Beckman Coulter, Abbott Architect, Mindray, Roche, Erba

- Tổng hợp và phân tích kết quả chạy mẫu

- Tính toán số liệu dựa trên phân mềm Excel 2010.

\section{KẾT QUẢ NGHIÊN CỨU VÀ BÀN LUÂN}

3.1. Xác định ngưỡng nồng độ cao, thấp, bình thường của 6 thông số hóa sinh. Chúng tôi thu thập và tham khảo các dữ liệu về khoảng tham chiểu của các thông số hoá sinh dựa trên các dữ liệu tổng hợp của ADA, ABIM, NORIP, CLSI EP7-A2, NHS, CDC và quyết định 320/QĐBYT của Bộ y tế về việc Ban hành tài liệu "Hướng dẫn quy trình kỹ thuật chuyên ngành Hoá sinh".

Đối với thông số glucose, nồng độ glucose bình thường trong máu ổn định từ 80-120 mg/dL $(4,44-6,66 \mathrm{mmol} / \mathrm{L})$. Theo $\mathrm{CDC}$, khoảng trị số bình thường với glucose máu khi đói là 74 - 109 $\mathrm{mg} / \mathrm{dL}(4,10-6,05 \mathrm{mmol} / \mathrm{L})$. Ngương cao theo CDC là của glucose máu khi đói là $>125 \mathrm{mg} / \mathrm{dL}$ $(6,94 \mathrm{mmo} / \mathrm{L})$, glucose máu bất kì là $>140 \mathrm{mg} / \mathrm{dL}$ (7,77 mmol/L). Ngưỡng giá trị cao theo Hiệp Hội Đái tháo đường Mỹ - ADA khuyến cáo với nồng độ glucose máu khi đói là 100 - $125 \mathrm{mg} / \mathrm{dL}$ (5,55 $6,95 \mathrm{mmol} / \mathrm{L}$ ) (tiền tiểu đường) và $\geq 126 \mathrm{mg} / \mathrm{dL}$ $(6,99 \mathrm{mmol} / \mathrm{L})$ (tiểu đường). Glucose máu bất kì ở ngưỡng cao là $\geq 200 \mathrm{mg} / \mathrm{dL}(11,1 \mathrm{mmo} / \mathrm{L})$ áp dụng không phân biệt độ tuổi và giới tính. Ngưỡng glucose máu thấp để xác định hạ đường huyết theo WHO khuyến cáo là dưới $45 \mathrm{mg} / \mathrm{dL}$ $(2,50 \mathrm{mmol} / \mathrm{L})$ ở người trưởng thành.

Đối với thông số AST và ALT, khoảng giá trị bình thường của ALT theo CDC khuyên cáo là 20 - $65 \mathrm{U} / \mathrm{L}$, của AST là $15-37 \mathrm{U} / \mathrm{L}$. Trong hầu hết các loại bệnh gan mức ALT thường cao hơn so với AST. Tuy nhiên cũng có một vài trường hợp ngoại lệ như viêm gan do rượu, xơ gan, chẩn thương do tắc nghẽn ống mật, chấn thương tim hoặc cơ. Trong viêm gan mạn tính, mức AST thường thấp hơn 4 lần so với giá trị bình thường. 
Chỉ số AST và ALT thấp thường gặp trong bệnh thận mãn tính, hoặc là dấu hiệu cảnh báo thiêý vitamin B6. Bảng 3.5, 3.6 thể hiện ngưỡng giá trị thay đổi của thông số ALT.

Khoảng giá trị bình thường của protein toàn phần theo CDC khuyến cáo là $64-82 \mathrm{~g} / \mathrm{L}$. Khoảng tham khảo theo Tổ chức Hóa sinh lâm sàng và Xét nghiệm y khoa Anh $(A C B$ - The Association for Clinical Biochemistry and Laboratory Medicine) là 60-80 $\mathrm{g} / \mathrm{L}$ ở người trưởng thành. Nồng độ cao hơn ngưỡng bình thường là chỉ dấu của tình trạng mất nước, nhiễm trùng mạn tính, rối loạn miễn dịch, u tủy. Nồng độ thấp hơn ngưỡng bình thường là kết quả của giảm một yễu tố protein cụ thể như albumin, kháng thể miễn dịch...

Theo $\mathrm{CDC}$, ngưỡng nồng độ cholesterol bình thường ở người lớn dưới $200 \mathrm{mg} / \mathrm{dl} \quad(5,17$ $\mathrm{mmol} / \mathrm{L})$ và dưới $170 \mathrm{mg} / \mathrm{dl}(4,40 \mathrm{mmol} / \mathrm{l})$ ở trẻ em. Theo WHO, ngưỡng bình thường $(<200$ $\mathrm{mg} / \mathrm{dL}$ ), khoảng ranh giới cao từ 200 - 239 $\mathrm{mg} / \mathrm{dL}(5,17-6,18 \mathrm{mmol} / \mathrm{L})$ và khoảng cao (> $239 \mathrm{mg} / \mathrm{dL})$.

Đối với triglyceride, $C D C$ công bố nồng độ triglyceride bình thường ở mức dưới $200 \mathrm{mg} / \mathrm{dl}$ $(2,26 \mathrm{mmol} / \mathrm{L})$, ngưỡng ranh giới cao là 200 $400 \mathrm{mg} / \mathrm{dl}(2,26-4,52 \mathrm{mmol} / \mathrm{L})$, mức nồng độ cao từ $400-1000 \mathrm{mg} / \mathrm{dl}(4,52-11,29 \mathrm{mmol} / \mathrm{L})$, mức rất cao trên $1000 \mathrm{mg} / \mathrm{dl}(11,29 \mathrm{mmol} / \mathrm{L})$. Ngưỡng nồng độ triglyceride rất cao được xác định là viêm tự cấp và cần tiếp nhận điều trị ngay.

Dựa vào các khoảng giá trị được tham khảo từ các công bố của các tổ chức uy tín trên thế giới, quyết định của Bộ Y tế, tờ LIQ CHEM ASY PREMIUM PLUS 1, 2, 3 của mẫu nội kiểm Randox và khoảng đo phân tích (AMR) trền 5 dòng máy phổ biến là Beckman Coulter, Abbott Architect, Mindray, Roche, Erba, nhóm nghiên cứu sẽ lựa chọn các ngưỡng giá trị cao, thấp và bình thường cho 6 thông số hoá sinh. Các khoảng nồng độ mà nhóm nghiên cứu lựa chọn được thể hiện qua bảng 1.

Bảng 1. Các khoảng nồng độ cao, thấp, binh thường của 6 thông số hoá sinh

\begin{tabular}{|c|c|c|c|c|c|c|c|c|c|}
\hline \multirow[b]{2}{*}{ Thông số } & \multirow{2}{*}{$\begin{array}{c}\text { Mức } \\
\text { nồng } \\
\text { độ }\end{array}$} & \multicolumn{8}{|c|}{ Khoảng Khoảng nồnđThiết bị và khoảng đo phân tích AMF Khoảng nồng } \\
\hline & & $\begin{array}{l}\text { nông độ } \\
\text { theo y vằ }\end{array}$ & $\begin{array}{c}\text { dọ theo mai } \\
\text { nội kiểm } \\
\text { Randox }\end{array}$ & $\begin{array}{c}\text { Beckman } \\
\text { Coulter }\end{array}$ & Roche & Erba & Abbott & Min & $\begin{array}{l}\text { độ lựa chọn } \\
\text { thí nghiệm }\end{array}$ \\
\hline \multirow{3}{*}{$\begin{array}{c}\text { Glucose } \\
(\mathrm{mmol} / \mathrm{L})\end{array}$} & $\mathrm{L}$ & $<3,90$ & $2,46-3,32$ & \multirow{3}{*}{$\begin{array}{l}0,3- \\
38,8\end{array}$} & \multirow{3}{*}{$\begin{array}{l}0,1- \\
83,3\end{array}$} & \multirow{3}{*}{$\begin{array}{l}0,1- \\
25,0\end{array}$} & \multirow{3}{*}{$\begin{array}{c}0,17- \\
71,5\end{array}$} & \multirow{3}{*}{$\begin{array}{c}0- \\
27,8\end{array}$} & $2,49-3,90$ \\
\hline & $\mathrm{N}$ & $2,50-7,00$ & $6,37-8,61$ & & & & & & $4,00-9,00$ \\
\hline & $\mathrm{H}$ & $>7,70$ & $16,8-22,7$ & & & & & & $9,50-24,00$ \\
\hline \multirow{3}{*}{$\begin{array}{c}\text { ALT } \\
(\mathbf{U} / L)\end{array}$} & $\mathrm{L}$ & $<7$ & 45-67 & \multirow{3}{*}{$\begin{array}{c}9- \\
1000\end{array}$} & \multirow{3}{*}{$\begin{array}{c}5- \\
700\end{array}$} & \multirow{3}{*}{$\begin{array}{l}4,4- \\
360\end{array}$} & \multirow{3}{*}{$1-1695$} & \multirow{3}{*}{$\begin{array}{c}0- \\
440\end{array}$} & $7-24$ \\
\hline & $\mathrm{N}$ & $7-68$ & $88-132$ & & & & & & $25-94$ \\
\hline & $\mathrm{H}$ & $>90$ & $\begin{array}{l}191-287 \\
\end{array}$ & & & & & & $95-300$ \\
\hline \multirow{3}{*}{$\begin{array}{l}\text { AST } \\
(\mathbf{U} / L)\end{array}$} & $\mathrm{L}$ & $<3$ & $446-70$ & \multirow{3}{*}{$\begin{array}{c}5- \\
400\end{array}$} & \multirow{3}{*}{$\begin{array}{c}5- \\
700\end{array}$} & \multirow{3}{*}{$\begin{array}{l}3,8- \\
390\end{array}$} & \multirow{3}{*}{$1-2092$} & \multirow{3}{*}{$\begin{array}{l}0- \\
40\end{array}$} & $7-24$ \\
\hline & $\mathrm{N}$ & $5-46,9$ & $123-185$ & & & & & & $25-94$ \\
\hline & $\mathrm{H}$ & $>80$ & $228-342$ & & & & & & $95-350$ \\
\hline \multirow{3}{*}{$\begin{array}{c}\text { Protein } \\
(\mathbf{g} / \mathbf{L})\end{array}$} & $\mathrm{L}$ & $<30$ & $32,8-49,2$ & \multirow{3}{*}{$\begin{array}{l}30- \\
120\end{array}$} & \multirow{3}{*}{$\begin{array}{c}4- \\
200\end{array}$} & \multirow{3}{*}{$\begin{array}{l}3,7- \\
150\end{array}$} & \multirow{3}{*}{$7,6-184$} & \multirow{3}{*}{$\begin{array}{c}0- \\
120\end{array}$} & $10-40$ \\
\hline & $\mathrm{N}$ & $55-90$ & $59,4-89,0$ & & & & & & $45-90$ \\
\hline & $\mathrm{H}$ & $>95$ & $72,8-109$ & & & & & & $95-115$ \\
\hline \multirow{3}{*}{$\begin{array}{c}\text { Cholestero } \\
(\mathrm{mmol} / \mathrm{L})\end{array}$} & $\mathrm{L}$ & $<4,00$ & $2,81-3,65$ & \multirow{3}{*}{$\begin{array}{l}0,13- \\
19,43\end{array}$} & \multirow{3}{*}{$\begin{array}{l}0,10- \\
20,69\end{array}$} & \multirow{3}{*}{\begin{tabular}{|c|}
$0,1-$ \\
17,97
\end{tabular}} & \multirow{3}{*}{$\begin{array}{l}1,08- \\
9,51\end{array}$} & \multirow{3}{*}{$\begin{array}{c}0- \\
18,10\end{array}$} & $2,50-3,70$ \\
\hline & $\mathrm{N}$ & $2,89-6,47$ & $4,45-5,77$ & & & & & & $3,80-6,10$ \\
\hline & $\mathrm{H}$ & $>6,20$ & $6,57-8,53$ & & & & & & $6,20-9,00$ \\
\hline \multirow{3}{*}{$\begin{array}{c}\text { Triglyceride } \\
(\mathrm{mmol} / \mathrm{L})\end{array}$} & $\mathrm{L}$ & - & $1,35-1,87$ & & & & & & $0,20-1,00$ \\
\hline & $\mathrm{N}$ & $0,46-5,60$ & $2,48-3,42$ & $0,10-$ & $0,10-$ & o, $10--$ & $0,10-$ & $0,00-$ & $1,10-2,60$ \\
\hline & $\mathrm{H}$ & $1,69-11,29$ & $3,40-4,70$ & & & & & & $2,70-9,50$ \\
\hline
\end{tabular}

Ghi chú: L: Nồng độ thấp; N: Nồng độ bình thường; $\mathrm{H}$ : Nồng độ cao

3.2. Kết quả khảo sát các ngưỡng nồng độ của 6 thông số hóa sinh trên các dòng máy xét nghiệm. Sau khi đã xác định được các giá trị ngưỡng nồng độ cho 6 thông số hoá sinh, chúng tôi tiến hành pha 5 bộ mẫu, mổi bộ gồm 3 mức nồng độ thấp, cao, bình thường để gửi cho 4 phòng xét nghiệm chạy trên 4 dòng máy Beckman AU680, Abbott Architect c8000, Mindray BA-88A, Roche Cobas c311 và 1 bộ mẫu chạy trên máy sinh hóa bán tự động dùng kit Erba ở phòng xét nghiệm Trung tâm Kiểm chuẩn xét nghiệm thành phỗ. Mỗi thông số chạy lặp lại 3 lần. Sử dụng kết quả của Trung tâm để làm giá trị ấn định cho mẫu pha chế, cụ thể như sau:

Bảng 2. Giá trị ấn định của mẫu hoá sinh 6 thông số ở các nồng độ cao, thấp và bình thường 


\begin{tabular}{|c|c|c|c|c|c|c|}
\hline & $\begin{array}{l}\text { Glucose } \\
\text { (mmol/L) }\end{array}$ & $\begin{array}{l}\text { Protein toàn } \\
\text { phân }(\mathrm{g} / \mathrm{L})\end{array}$ & $\begin{array}{l}\text { Cholesterol } \\
\text { (mmol/L) }\end{array}$ & $\begin{array}{c}\text { Triglyceride } \\
\text { (mmol/L) }\end{array}$ & $\begin{array}{l}\text { AST } \\
\text { (U/L) }\end{array}$ & $\begin{array}{c}\text { ALT } \\
(\mathbf{U} / L)\end{array}$ \\
\hline $\begin{array}{c}L(M \pm S D) \\
(n=3)\end{array}$ & $\begin{array}{c}2,81 \pm \\
0,01\end{array}$ & $\begin{array}{c}29,87 \pm \\
0,67\end{array}$ & $\begin{array}{c}2,49 \pm \\
0,02 \\
\end{array}$ & $\begin{array}{c}0,58 \pm \\
0,01 \\
\end{array}$ & $\begin{array}{c}21,20 \pm \\
0,30 \\
\end{array}$ & $\begin{array}{c}19,13 \pm \\
0,35 \\
\end{array}$ \\
\hline $\begin{array}{c}N(M \pm S D) \\
(n=3)\end{array}$ & $\begin{array}{c}12,26 \pm \\
0,04\end{array}$ & $\begin{array}{c}55,9 \pm \\
0,20\end{array}$ & $\begin{array}{c}4,06 \pm \\
0,02\end{array}$ & $\begin{array}{c}1,69 \pm \\
0,02\end{array}$ & $\begin{array}{c}71,60 \pm \\
0,46\end{array}$ & $\begin{array}{c}53,73 \pm \\
0,40\end{array}$ \\
\hline $\begin{array}{c}H(M \pm S D) \\
(n=3)\end{array}$ & $\begin{array}{c}17,35 \pm \\
0,06\end{array}$ & $\begin{array}{c}112,37 \pm \\
0,74\end{array}$ & $\begin{array}{c}6,82 \pm \\
0,09\end{array}$ & $\begin{array}{c}2,94 \pm \\
0,09\end{array}$ & $\begin{array}{c}136,03 \pm \\
0,25\end{array}$ & $\begin{array}{c}116,87 \pm \\
0,65\end{array}$ \\
\hline
\end{tabular}

Kết quả phân tích 6 thông số hoá sinh trên 4 dòng máy thể hiện trong hình 1, 2, 3, 4, 5, 6.

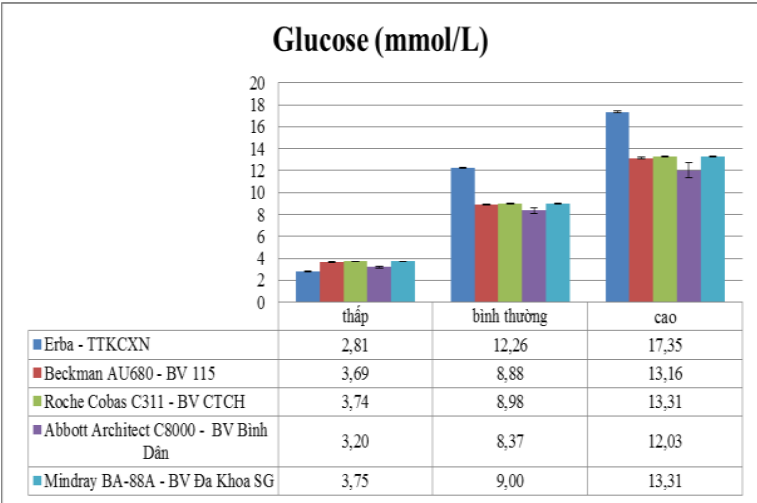

Hình 1. Kết quả phân tích glucose trên 5 dòng máy ở 3 mức nồng độ thấp, bình thường và cao

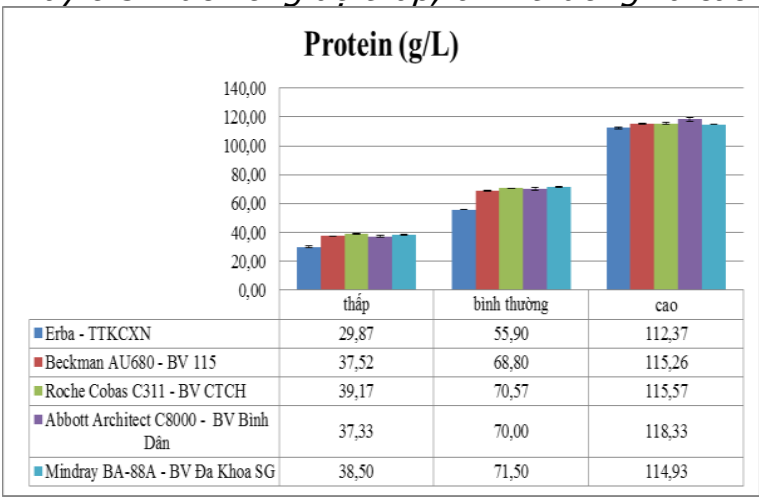

Hình 2. Kết quả phân tích protein trên 5 dòng máy ở 3 múc nồng độ thấp, binh thường và cao

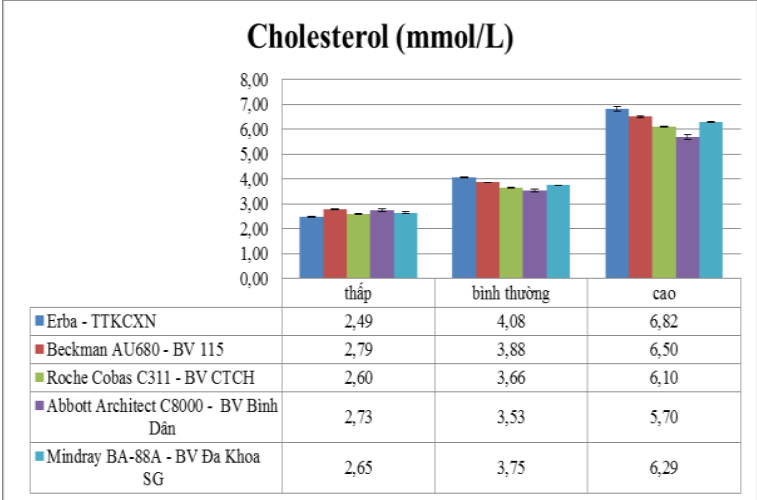

Hình 3. Kết quả phân tích cholesterol trên 5 dòng máy ở 3 mức nồng độ thấp, binh thường và cao

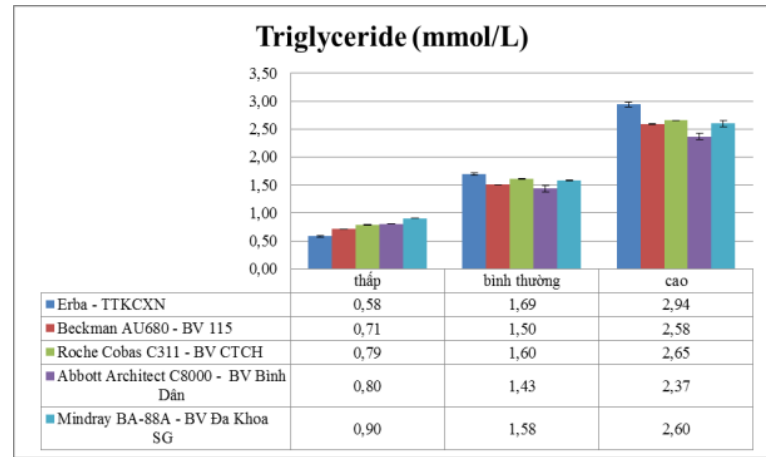

Hình 4. Kết quả phân tích triglyceride trên 5 dòng máy ở 3 mức nồng độ thấp, binh thường và cao

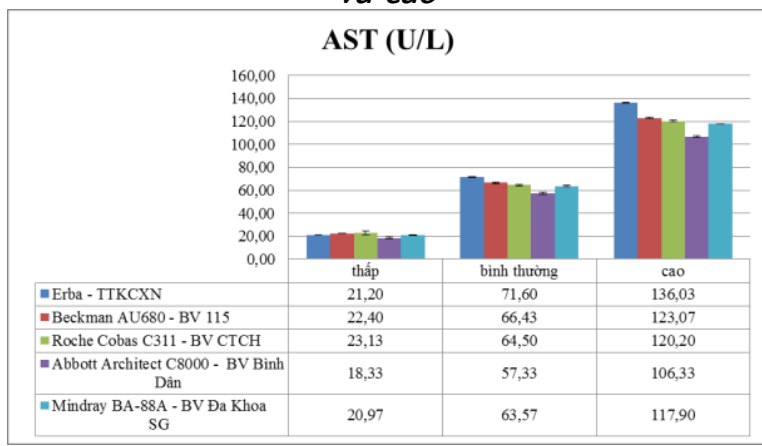

Hinh 5. Kết quả phân tích AST trên 5 dòng máy ở 3 mức nồng độ thấp, bình thường và cao

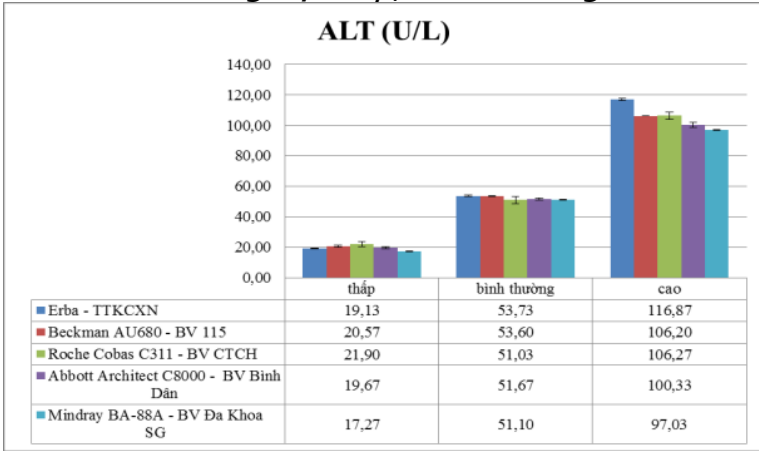

Hinh 6. Kết quả phân tích ALT trên 5 dòng máy ở 3 mức nồng độ thấp, binh thường và cao Kết quả từ 5 phòng xét nghiệm cho thấy 5 dòng máy đều có thể đọc được các mẫu ở các ngưỡng giá trị cao, thấp, bình thường và các giá trị đọc được không có sự sai khác nhiều. Giá trị 
CV\% của 6 thông số ở 3 mức nồng đô đều nhỏ hơn $0,1 \%$. Như vậy, các ngưỡng giá trị mà nhóm nghiên cứu đưa ra là phù hợp và sẽ được sử dụng làm khoảng biến thiên của 6 thông số trong phương pháp tối ưu hoá các thành phần môi trường bảo quản mẫu.

\section{KẾT LUÂNN}

Nhóm nghiên cứu đã tiến hành khảo sát các giá trị ngưỡng thay đổi của 6 thông số thông qua các tài liệu y văn về ngưỡng bệnh lý, khoảng đo phân tích của thiết bị xét nghiệm để xác định các mức nồng độ cao, bình thường, thấp dùng trong pha chế mẫu. Kết quả thu được khoảng nồng độ cao của glucose là $9,50-24,00 \mathrm{mmol} / \mathrm{L}$, protein là 95 - $115 \mathrm{~g} / \mathrm{L}$, cholesterol là $6,20-9,00$ $\mathrm{mmol} / \mathrm{L}$, triglyceride là $2,70-9,50 \mathrm{mmol} / \mathrm{L}$, AST là $95-350 \mathrm{U} / \mathrm{L}$, ALT là $95-300 \mathrm{U} / \mathrm{L}$; khoảng nồng độ thấp của glucose là $2,49-3,90 \mathrm{mmol} / \mathrm{L}$, protein là $10-40 \mathrm{~g} / \mathrm{L}$, cholesterol là $2,50-3,70$ $\mathrm{mmol} / \mathrm{L}$, triglyceride là $0,20-1,00 \mathrm{mmol} / \mathrm{L}$, AST là 7 - 24 U/L, ALT là 7 - 24 U/L; khoảng nồng độ bình thường của glucose là $4,00-9,00 \mathrm{mmol} / \mathrm{L}$, protein là $45-90 \mathrm{~g} / \mathrm{L}$, cholesterol là $3,80-6,10$ $\mathrm{mmol} / \mathrm{L}$, triglyceride là $1,10-2,60 \mathrm{mmol} / \mathrm{L}$, AST là $25-94 \mathrm{U} / \mathrm{L}$, ALT là 25 - $94 \mathrm{U} / \mathrm{L}$. Để kiểm chứng kết quả thu được, 4 bộ mẫu được gửi đến 4 phòng xét nghiệm để phân tích. Kểt quả thu được là các dòng máy lựa chọn đều đọc được mẫu ở 3 mức nồng độ và kết quả giữa các dòng máy không có sự khác biệt nhiều.

KIẾN NGHİ. Sử dụng kết quả nghiên cứu để pha chế mẫu ngoại kiểm hóa sinh theo các tình trạng bệnh lý khác nhau, từ đó góp phần đảm bảo chất lượng xét nghiệm và nâng cao năng lực của các phòng xét nghiệm.

\section{TÀI LIÊU THAM KHẢO}

1. Bộ Y Tế (2014), Quyết định về việc ban hành tài liệu "Hướng dẫn quy trình kỹ thuật chuyên ngành Hóa sinh, Hà Nội.

2. Trân Hữu Tẩm và Lê Thị Thùy Như (2019), Nội kiểm tra chất lượng xét nghiệm, xuất bản lần 5 , Nhà xuất bản y hợ, TP.HCM.

3. Trân Hữu Tâm và cộng sự (2020), Ngoại kiểm tra chất lượng xét nghiệm, xuất bản lần 4, Nhà xuất bản y hoc, TP.HCM.

4. Solberg HË. Dybkaer R (1987), Approved recommendation on the theory of reference values, Part 6: Presentation of observed values related to reference values, International Federation of Clinical Chemistry (IFCC) - Clin Chim Acta, 170(S33-42).

5. Antony Barker Graham Jones (2008), Reference Intervals, Clin Biochem Rev, 29, 93-97. CraigJackson

\section{ĐĂC ĐIỂM TỔN THƯƠNG Ở CÁC TRƯờNG HỢP CHẤN THƯƠNG MŨI, XOANG QUA GIÁM ĐİNH PHÁP Y THƯƠNG TÍCH}

\section{TÓM TẮT.}

Mục tiêu: Mô tả đặc điểm tổn thương ở các trường hợp chấn thương mũi, xoang qua giám định pháp y thương tích. Đối tượng và phương pháp nghiên cứu: Nghiên cứu mố tả cắt ngang trên 98 trường hợp chấn thương mũi, xoang được giám định xác định tỷ lệ thương tích tại Viện Pháp y quốc gia từ tháng $01 / 2016$ đến tháng $10 / 2020$. Kết quả nghiên cứu: Gãy xương mũi chiếm tỷ lệ cao nhất $56,12 \%$, tổn thương xoang chiếm $35,71 \%$, seo phần mềm chiếm $25,51 \%$, vẹo vách ngăn mũi chiếm $14,29 \%$, kết hợp sẹo và tổn thương mũi xoang 4,08\%, tổn thương mũi, xoang với các tổn thương khác $21,43 \%$. Có $85,71 \%$ không có di chứng liên quan đến chức năng mũi, xoang chiếm tỷ lệ cao nhất, ảnh hưởng đến hạn chế mức độ thở là $3,06 \%$, viêm mũi xoang $6,12 \%$, di

*Viện Pháp y quốc gia

Chịu trách nhiệm chính: Nguyễn Đức Nhự

Email: nhund76@gmail.com

Ngày nhận bài: 21.6.2021

Ngày phản biên khoa họ: 20.8.2021

Ngày duyệt bài: 27.8.2021

\section{Nguyễn Đức Nhự, Trần Anh Tuấn}

chứng khác là 5,10\%. Kết quả phát hiện tổn thương trùng hợp với chẩn đoán của bệnh viển là $84,69 \%$, không truung hợp là $15,31 \%$. Vật gây thương tích do vật tày chiếm tỳ lệ cao nhất là $45,92 \%$, vật sắc, nhọn chiếm $13,27 \%$, hỏa khí $1,02 \%$, không rõ vật gây thương tích là $3,06 \%$, không yêu câuu giám định vật gây thương tích là $36,73 \%$.

Tư khóa: Chấn thương mũi, xoang, giám định pháp y thương tích.

\section{SUMMARY}

\section{CHARACTERISTICS OF INJURY IN CASES} OF NASAL AND SINUS TRAUMA THROUGH

\section{FORENSIC MEDICINE EXAMINATION}

Objectives: To describe the characteristics of injuries in cases of nasal and sinus trauma through forensic medicine examination. Subjects and methods: A cross-sectional descriptive study on 98 cases of nasal and sinus trauma assessed to determine the rate of injury at the National Institute of Forensic Medicine from January 2016 to October 2020. Research results: Nose fractures accounted for the highest rate of $56.12 \%$, sinus lesions accounted for $35.71 \%$, soft tissue scars accounted for $25.51 \%$, 